\title{
On the Sensitivity of Firms' Investment to Cash Flow AND UNCERTAINTY
}

\author{
Christopher F Baum* \\ Boston College and DIW Berlin \\ Mustafa Caglayan \\ University of Sheffield \\ Oleksandr Talavera \\ Aberdeen Business School
}

August 12, 2008

\begin{abstract}
We investigate the analytical and empirical linkages between cash flow, uncertainty and firms' capital investment behavior. Our empirical approach constructs measures of own- and market-specific uncertainty from firms' daily stock returns and S\&P 500 index returns along with a CAPM-based risk measure. Our results indicate that even in the presence of important firm-specific variables, uncertainty is an important determinant of firms' investment behavior. Depending on the measure of uncertainty used, investment may be stimulated or curtailed by the effects of uncertainty on its own or through its interactions on cash flow.
\end{abstract}

Keywords: capital investment, cash flow, uncertainty, CAPM

JEL: E22, D81, C23

${ }^{*}$ We are grateful for comments received from seminar participants at Koç University, the University of Strathclyde and the 13th International Conference on Panel Data, University of Cambridge, Fabio Schiantarelli and the constructive suggestions of an anonymous reviewer. Corresponding author: Christopher F Baum, Department of Economics, Boston College, Chestnut Hill, MA 02467 USA, Tel: 617-552-3673, fax 617-552-2308, e-mail: baum@bc.edu. 


\section{Introduction}

It is well known that the variability of private investment spending accounts for the bulk of business fluctuations. To that end several theoretical studies have examined the extent to which uncertainty affects aggregate or firmspecific capital accumulation. This literature concentrates on the impact of uncertainty arising from various sources which affects managers' decisions about the timing and the quantity of fixed capital investment. ${ }^{1}$ In our research we extend the standard Tobin's $Q$ model in order to analyze the impacts of cash flow and uncertainty - which may arise from various sources - on the firm's investment decision problem.

As many researchers have shown, when uncertainty varies over time, potential lenders may be less able to accurately assess the firm's creditworthiness, limiting the firm's ability to raise external funds. In such circumstances, firms may become 'liquidity constrained' as the risk premium that lenders require to provide funds increases along with the uncertainty in the environment. Hence, it would not be surprising to find that variations in uncertainty have significant effects on firms' investment behavior. Yet, although the earlier empirical research has successfully captured liquidity effects through the introduction of cash flow into the basic $Q$ model, to our knowledge, no previous study has investigated whether the impact of cash flow on capital investment strengthens or weakens as uncertainty varies over time. Furthermore, earlier research generally concentrates on the impact of a single type of uncertainty measure on firms' capital investment behavior. In this paper we propose a dynamic investment model to scrutinize the impact of several forms of uncertainty which may affect investment on their own or in conjunction with cash flow. Our model, therefore, reveals the interlinkages between uncertainty, firms' cash flow and capital investment behavior.

We specifically consider the effects of three different forms of uncertainty on firms' cost of external funds, and thus on their investment behavior: Own (intrinsic) uncertainty, derived from firms' stock returns; Market (extrinsic)

\footnotetext{
${ }^{1}$ See Hartman (1972), Abel (1983), Bernanke (1983), Craine (1989), Dixit and Pindyck (1994), Caballero (1999).
} 
uncertainty, driven by $\mathrm{S} \& \mathrm{P} 500$ index returns, ${ }^{2}$ and the relations between intrinsic and extrinsic uncertainty. To capture the latter effect, we introduce a covariance term (our CAPM-based risk measure) and allow the data to determine the differential impact of each of these components on the firm's capital investment behavior. These uncertainty factors, standing alone or interacted with firm cash flow, serve to proxy the shadow price of external finance in our analytical framework.

We employ annual firm-level U.S. manufacturing sector data obtained from COMPUSTAT and match it to firm-level daily financial data from CRSP over the 1984-2003 period. Daily stock returns and market index returns are utilized to compute intrinsic and extrinsic uncertainty via method based on Merton (1980) from the intra-annual variations in stock returns and aggregate financial market series. This approach provides a more representative measure of the perceived volatility while avoiding potential problems: for instance, the high persistence of shocks or low correlation in volatility. In that respect, our study improves upon much of the literature in its method of using high-frequency data to quantify volatility evaluated at a lower frequency. $^{3}$

The results of the paper can be summarized as follows. In contrast to earlier research such as Leahy and Whited (1996), we find a significant role for each uncertainty measure while factors such as cash flow and the debt ratio maintain their significance in explaining firm investment behavior. ${ }^{4}$ Our empirical model evaluates how the effects of uncertainty on investment may be strengthened or weakened by the firm's current financial condition. We observe that a CAPM-based uncertainty measure has a significant direct effect on the firm's fixed investment. Furthermore, its effects through cash flow, along with those of intrinsic uncertainty, are significant but vary in sign over the range of cash flow values. Interestingly, we find that while

\footnotetext{
${ }^{2}$ In this paper we use the terms $O w n$, idiosyncratic and intrinsic uncertainty interchangeably. Likewise, Market is taken as synonymous with extrinsic uncertainty.

${ }^{3}$ Leahy and Whited (1996), Bloom, Bond and Van Reenen (2007), Bond and Cummins (2004) have also utilized daily stock returns to compute firm-level uncertainty. However, the methodology they used to generate a proxy for uncertainty is different from ours.

${ }^{4}$ An exception are the findings of Baum, Caglayan and Talavera (2008), which also display a significant role for similar measures of uncertainty. However, their analysis does not consider interactions of uncertainty with cash flow.
} 
the effects of Own uncertainty through cash flows on firms' fixed investment is positive, that of Market uncertainty is negative. In contrast to those of Bloom et al. (2007), our findings suggest that (although the two models differ) different types of uncertainty can enhance or impair fixed investment by themselves or through cash flow, potentially clouding the relationship between investment and uncertainty (Boyle and Guthrie (2003)). We also show that the impact of cash flow on capital investment changes as the underlying uncertainty varies.

The rest of the paper is constructed as follows. Section 2, though not comprehensive given the vast literature on capital investment, provides a brief survey of the empirical literature discussing the effects of uncertainty on investment. Section 3 presents the modeling framework and discusses the methodology we employ in our investigation. Section 4 documents the data and our empirical findings, while Section 5 concludes and draws implications for future research.

\section{The empirical literature on investment and un- certainty}

Researchers have expended considerable effort in trying to understand the linkages between uncertainty and firm-level and aggregate investment behavior. Fluctuations in aggregate investment can arise from various sources of uncertainty. For instance, many researchers have studied the impact of exchange rate uncertainty on aggregate or industry level investment behavior. To that end Goldberg (1993) shows that exchange rate uncertainty has a weak negative effect on investment spending. Campa and Goldberg (1995) find no significant impact of exchange rate volatility on investment. Darby, Hallett, Ireland and Piscatelli (1999) provide evidence that exchange rate uncertainty may or may not depress investment, while Serven (2003) un-

earths a highly significant negative impact of real exchange rate uncertainty on private investment in a sample of developing countries.

Many other researchers have investigated the importance of uncertainty arising from output, prices (inflation), taxes and interest rates. Driver and Moreton (1991) conclude that while a proxy for uncertainty driven from 
output growth has a negative long-run effect on aggregate investment, the measure of uncertainty obtained from inflation has none. Calcagnini and Saltari (2000) suggest that while demand uncertainty has a significant negative effect on investment, interest rate uncertainty has none. Huizinga (1993) reports a negative effect on investment for uncertainty proxies obtained from wages and raw materials prices, but a positive effect for a proxy obtained from output prices. Ferderer (1993) captures a measure of uncertainty on long term bonds using the term structure of interest rates and finds a negative impact on aggregate investment. Hurn and Wright (1994) find that the linkage between oil price variability and the decision to develop an oil field (more specifically the North Sea oil field) is not significant. Pindyck and Solimano (1993) use the variance in the marginal revenue product of capital as a proxy for uncertainty to study an implication of irreversible investment models to find the effects of uncertainty on the investment trigger. Edmiston (2004) investigates the role of tax uncertainty on investment and finds a significant negative effect between the two. ${ }^{5}$

Turning now to research which has used firm level data, we also see several studies employing measures of uncertainty that emerge from movements in exchange rates, output, demand, firm-specific liquidity, inflation or a CAPM framework. ${ }^{6}$ Brainard, Shoven and Weiss (1980) find that a CAPMbased risk measure yields mixed results on the linkages between investment and their uncertainty measure. Ghosal and Loungani (1996) report a negative role of output uncertainty on investment. Leahy and Whited (1996), using risk measures constructed from stock return data, argue that uncertainty exerts a strong negative effect on investment and point out that uncertainty affects investment directly rather than through covariances. Guiso and Parigi (1999) investigate the impact of demand uncertainty using firm level data to show that uncertainty weakens the response to demand and slows down capital accumulation. Minton and Schrand (1999) find evidence that cash flow volatility is costly and leads to lower levels of investment in

\footnotetext{
${ }^{5}$ See Edmiston (2004) for other studies that concentrate on the linkages between investment and volatility in taxes.

${ }^{6}$ Some researchers have studied the extent to which a proxy for analysts' forecasts can explain firms' investment behavior; see among others Abel and Eberly (2002).
} 
capital expenditures, R\&D and advertising. Beaudry, Caglayan and Schiantarelli (2001) show that macroeconomic uncertainty captured through inflation variability has a significant effect on investment behavior of firms. Bloom et al. (2007) suggest that higher uncertainty renders firms more cautious and reduces the effects of demand shocks on investment. Boyle and Guthrie (2003) argue that offsetting effects of payoff and financing uncertainty must be distinguished in order to accurately gauge their effects on investment.

Although these studies summarized above have examined various aspects of the linkages between uncertainty and investment, none of them have entertained the impact of intrinsic or extrinsic uncertainty and a CAPM-based risk measure in a regression model. Furthermore, our investigation scrutinizes uncertainty-cash flow interactions to explain firms' investment behavior along with three of the basic elements: $Q$, cash flow and leverage. Finally, our choice of methodology to compute a measure of uncertainty is different from the rest of the literature and has specific advantages as discussed in section 3.1 below.

In the next section, we discuss the analytical model used to link uncertainty faced by the firm to its choice of an optimal investment plan as well as the method that we use to obtain our proxies for uncertainty.

\section{An extended $Q$ model of firm value optimization}

The theoretical model proposed in this paper is based on the firm value optimization problem and represents a generalization of the standard $Q$ models of investment by Blundell, Bond, Devereux and Schiantarelli (1992). The present value of the firm is equated to the expected discounted stream of $D_{t}$, dividends paid to shareholders, where $0<\rho<1$ is the constant one-period discount factor:

$$
V_{t}=\max E_{t}\left[\sum_{s=0}^{\infty} \rho^{s} D_{t+s}\right] .
$$

At time $t$, all present values are known with certainty while all future variables are stochastic. Dividends can be substituted into (1) using the follow- 
ing definition of sources and uses of funds:

$$
D_{t}=\Pi\left(K_{t}\right)-C\left(I_{t}, K_{t}, \zeta_{t}\right)-I_{t}+B_{t+1}-B_{t} R_{t},
$$

where $\Pi\left(K_{t}\right)$ denotes the value of current profits given the beginning of the period capital stock. $C\left(I_{t}, K_{t}, \zeta_{t}\right)$ is the real cost of adjusting $I_{t}$ units of new capital, and $\zeta_{t}$ is an additive shock to adjustment costs. The functions $\Pi\left(K_{t}\right)$ and $C\left(I_{t}, K_{t}, \zeta_{t}\right)$ are continuous and differentiable. External funds are denoted by $B_{t}$ and are associated with firm-specific financing costs of $R_{t}$, the gross interest rate. All financial measures are expressed in real terms. In order to isolate the role of debt financing we assume that equity financing is prohibitively expensive so that firms prefer debt financing only. Furthermore, managers are assumed to have rational expectations. The firm maximizes equation (1) subject to two constraints:

$$
\begin{aligned}
& K_{t}=(1-\delta) K_{t-1}+I_{t}, \\
& B_{t+1} \leq B_{t+1}^{*} .
\end{aligned}
$$

The first equation represents evolution of the capital stock $K_{t}$ where $I_{t}$ is gross investment expenditures and $\delta$ is the rate of capital depreciation. Financial frictions are introduced through the firm-specific cost of funds as described below. We assume that the firm's borrowing is less than a debt ceiling $B_{t+1}^{*}$, specific to the firm, which depends on unobservable proxies of financial health. ${ }^{7}$ Finally, the firm faces the transversality condition which prevents the firm from borrowing an infinite amount and paying it out as dividends:

$$
\lim _{T \rightarrow \infty}\left[\prod_{j=t}^{T-1} \rho_{j}\right] B_{T}=0, \forall t .
$$

The first order conditions of this maximization problem for investment, capital and debt are

$$
\begin{aligned}
\frac{\partial C_{t}}{\partial I_{t}}+1 & =\lambda_{t}, \\
\frac{\partial \Pi_{t}}{\partial K_{t}}-\frac{\partial C_{t}}{\partial K_{t}} & =\lambda_{t}-(1-\delta) \rho E_{t} \lambda_{t+1}, \\
E_{t}\left[\rho R_{t+1}\right] & =1+\mu_{t},
\end{aligned}
$$

\footnotetext{
${ }^{7}$ See Hubbard, Kashyap and Whited (1995) for a similar modeling strategy.
} 
where the Lagrange multipliers $\lambda_{t}$ and $\mu_{t}$ represent the shadow prices associated with the capital accumulation and the borrowing constraint, respectively. Equation (6) sets the marginal cost associated with an additional unit of investment equal to its shadow price. Equation (7) denotes the firstorder condition for capital and defines the Euler equation which describes the evolution of $\lambda_{t}$. Equation (8) defines the Lagrange multiplier $\mu_{t}$ which represents the additional cost (over the risk-free rate) that the firm will face in the presence of financial frictions. In a world without financial frictions, $\mu_{t}=0$ and $E_{t}\left[\rho R_{t+1}\right]=1$, implying that firms can borrow at the risk-free rate. Assuming linear homogeneity of the profit function $\Pi\left(K_{t}\right)=\left(\partial \Pi_{t} / \partial K_{t}\right) K_{t}$ and the cost function $C\left(K_{t}, I_{t}\right)=\left(\partial C_{t} / \partial I_{t}\right) I_{t}+\left(\partial C_{t} / \partial K_{t}\right) K_{t}$, we combine the first order conditions for investment and capital, Equations (6) and (7), to yield

$$
\lambda_{t}(1-\delta) K_{t-1}=D_{t}+B_{t+1}-R_{t} B_{t}+\rho E_{t}\left[\lambda_{t+1}(1-\delta) K_{t}\right] .
$$

Solving this equation forward and using the first order condition for debt (8) and the definition of the value of the firm (1), we can show that marginal $q_{t}$ is equal to the shadow value of an additional unit of capital, $\lambda_{t}$,

$$
q_{t}=\lambda_{t}=\frac{V_{t}}{(1-\delta) K_{t-1}}-\frac{R_{t}}{(1-\delta)} \frac{B_{t}}{K_{t-1}}-\frac{\Theta_{t}}{K_{t-1}},
$$

where the last term $\Theta_{t} / K_{t-1}$ represents the expectation of the infinite sum $\sum_{i=0}^{\infty} \rho^{i}\left(B_{t+i+1} \mu_{t+i}\right)$. This term equals zero when the shadow price of external finance is equal to zero, $\mu_{t}=\mu_{t+i}=0 \forall i$. We define average $Q$ as $Q_{t}=V_{t} / K_{t-1}$ and the leverage ratio as $B_{t} / K_{t-1}$. For the unlevered firm marginal q is equal to average $\mathrm{Q}$ in the case of no borrowing constraint. ${ }^{8}$

Similar to Love (2003), we assume that adjustment costs are quadratic and take the form

$$
C\left(I_{t}, K_{t}, \varepsilon\right)=\frac{b}{2}\left[\left(\frac{I_{t}}{K_{t}}\right)-g\left(\frac{I_{t-1}}{K_{t-1}}\right)-a+\varepsilon_{t}\right]^{2} K_{t} .
$$

To obtain an investment equation, we rewrite the first order condition (6) making use of the functional form of adjustment costs:

$$
\frac{I_{t}}{K_{t}}=a-\frac{1}{b}+g \frac{I_{t-1}}{K_{t-1}}+\frac{1}{b(1-\delta)} Q_{t}-\frac{R_{t}}{b(1-\delta)} \frac{B_{t}}{K_{t-1}}-\frac{1}{b} \frac{\Theta_{t}}{K_{t-1}} .
$$

\footnotetext{
${ }^{8}$ Hennessy (2004) obtains a similar result in which average $Q$ overstates marginal $q$ by incorporating post-default returns to investment.
} 
The last term in Equation (12) captures the role of financial frictions in the firm's capital investment behavior. Many researchers have documented that financially constrained firms show greater sensitivity to the availability of internal finance. ${ }^{9}$ We propose that the extent of financial friction is related not only to the firm's cash flow but also to the magnitude of uncertainty faced by the firm. ${ }^{10}$ Prospective lenders evaluate their expected return on a loan to the firm considering the likelihood of the firm's default. When making a lending decision, they take into account not only observable cash flows but also uncertainty related to the firm and its environment. When macroeconomic or firm-specific uncertainty fluctuates, lenders alter their loan premium over the risk-free rate. Higher loan premia will cause the firms' managers to be more cautious in their investment decisions.

We formulate the magnitude of the financial friction facing a firm, $\Theta_{t} / K_{t-1}$, as a function of the firm's liquidity $\frac{C F_{t}}{K_{t-1}}$ as well as measures of uncertainty on their own and interacted with the liquidity measure. ${ }^{11}$

$\frac{\Theta_{t}}{K_{t-1}}=c_{1} \eta_{i, t-1}+c_{2} \varepsilon_{t-1}+c_{3} \nu_{i, t-1}+\frac{C F_{t}}{K_{t-1}}\left(1+a_{1}+a_{2} \eta_{i, t-1}+a_{3} \varepsilon_{t-1}+a_{4} \nu_{i, t-1}\right)$

where $C F_{t}$ is cash flow. The above form introduces three specific measures of uncertainty: intrinsic uncertainty $(\eta)$, or uncertainty driven by the firm's stock returns; extrinsic uncertainty $(\varepsilon)$, or uncertainty driven by S\&P 500 index returns; and the covariance between firm and market returns, $\nu$ : a CAPM-based risk measure. ${ }^{12}$ Uncertainty would naturally emerge from various sources such as the behavior of prices, wages, consumers' tastes, technology, institutions, exchange rates and other factors. Given one or more of these sources would be operational when lenders evaluate the firm's creditworthiness, we believe that use of firm-specific daily returns can provide us with a single proxy which embodies all potential sources of uncertainty relevant to the firm. Furthermore, using intrinsic and extrinsic uncertainty in our regressions we can determine whether investment behavior is more

\footnotetext{
${ }^{9}$ See, for example, Almeida, Campello and Weisbach (2004).

${ }^{10}$ For instance, see Bloom et al. (2007) for a discussion of similar issues.

${ }^{11} \Theta_{t} / K_{t-1}$ is a function of uncertainty and liquidity, evaluated as the ratio of cash flow to the lagged capital stock. We apply a first-order Taylor expansion to those factors to derive this expression.

${ }^{12}$ We explain how these measures are constructed using daily data in section 3.1.
} 
sensitive to own- or market-specific uncertainty. Also, the covariance term helps us evaluate the predictions arising from the CAPM. We include lagged uncertainty measures to capture the effect that investment plans have been formulated based on the prior period's observed levels of uncertainty. Although we do not have an a priori expectation regarding the signs of the coefficients of uncertainty measures, it is generally considered that while higher levels of cash flow relax borrowing constraints, higher levels of uncertainty increase financial frictions, leading to a negative relationship between investment and uncertainty.

In our empirical implementation, we estimate Equation (12) using the parameterization of $\Theta_{t} / K_{t-1}$ as above.

$$
\begin{array}{r}
\left(\frac{I_{i, t}}{K_{i, t-1}}\right)=\beta_{0}+\beta_{1}\left(\frac{I_{i, t-1}}{K_{i, t-2}}\right)+\beta_{2} Q_{i t}+\beta_{3}\left(\frac{C F_{i, t}}{K_{i, t-1}}\right)+ \\
\beta_{4}\left(\frac{B_{i, t-1}}{K_{i, t-2}}\right)+\gamma_{1} \eta_{i, t-1}+\gamma_{2} \varepsilon_{t-1}+\gamma_{3} \nu_{i, t-1}+ \\
\left(\frac{C F_{i, t}}{K_{i, t-1}}\right) \times\left(\omega_{1} \eta_{i, t-1}+\omega_{2} \varepsilon_{t-1}+\omega_{3} \nu_{i, t-1}\right)+\kappa_{i}+\epsilon_{i t}
\end{array}
$$

where $i$ indexes the firm, $\kappa_{i}$ captures the firm fixed effect and $\epsilon_{i t}$ denotes the error term. The beginning of period average $Q$ is defined as the market value of the firm (shares plus debt) net of the value of current assets (inventories and financial assets) divided by the replacement value of the firm's capital stock, imputed by the method of Salinger and Summers (1983). ${ }^{13}$ Finally, $I$ is investment, $C F$ denotes cash flow and $B$ is the firm's debt. All terms are deflated by the consumer price index taking into account the timing of the variables appearing in the numerator and denominator.

The model above basically augments the standard investment model with direct and indirect effects of several uncertainty measures. Given earlier empirical and theoretical findings, we expect $\beta_{1}, \beta_{2}$ and $\beta_{3}$ to be positive and $\beta_{4}$ to be negative. We also anticipate that the cash flow sensitivity of investment should increase in the presence of heightened uncertainty as captured through the interaction terms.

\footnotetext{
${ }^{13}$ This methodology was also employed by Leahy and Whited (1996).
} 
To summarize, our model contains three of the basic elements, $Q$, cash flow and leverage, which have been shown to explain the investment behavior of firms, along with three different measures of uncertainty. By using intrinsic and extrinsic uncertainty in our regressions, by themselves and interacted with a measure of the firm's liquidity, we can determine whether investment behavior is more sensitive to Own- or Market-specific uncertainty while the covariance term helps us evaluate the predictions arising from the CAPM. The interaction terms in the model allow us to examine whether uncertainty makes managers more cautious in their investment decisions as Bloom et al. (2007) claim.

\subsection{Generating volatility measures from daily data}

Any attempt to evaluate the effects of uncertainty on the firm investment behavior requires specification of a measure of risk. The empirical literature offers a number of competing approaches for the construction of volatility measures. The choice of a particular specification to generate uncertainty may have a considerable impact on the empirical findings as counterintuitive results may be merely reflecting errors of measurement in a proxy for risk. It is possible to employ a simple moving standard deviation of the return series, at the same frequency as the data: for instance, including the past four or eight quarters of changes in the context of quarterly data. However, this measure gives rise to substantial serial correlation in the summary measure. A more sophisticated approach utilises the ability of GARCH models to mimic the "volatility clustering" often found in high-frequency financial series. However, a GARCH model fitted to monthly or quarterly data may find very weak persistence of shocks. Furthermore, a proxy for uncertainty obtained from a GARCH specification will be dependent on the choice of the model and exhibit significant variation over alternatives.

In this study, we utilize daily stock returns and market index returns to compute intrinsic and extrinsic uncertainty via a method based on Merton (1980) from the intra-annual variations in stock returns and aggregate financial market series. ${ }^{14}$ This approach provides a more representative measure

\footnotetext{
${ }^{14}$ See Baum, Caglayan and Ozkan (2004) for a more detailed discussion of the procedure
} 
of the perceived volatility while avoiding potential problems raised above. Also the use of daily returns on the stock provides one with a forward-looking proxy for the volatility of the firms' environment.

In order to employ the Merton methodology to the problem at hand, we must compute the intra-annual volatility of the series from daily data. We first take the squared first difference of the daily changes in returns (after dividing by the square root of the number of days intervening), which is then defined as the daily contribution to annual volatility:

$$
\varsigma_{t}^{d}=\left(100 \frac{\Delta x_{t}}{\sqrt{\Delta \phi_{t}}}\right)^{2}
$$

where the denominator expresses the effect of calendar time elapsing between observations on the $x$ process. If data were generated every calendar day, $\Delta \phi_{t}=1, \forall t$, but given that data are not available on weekends and holidays, $\Delta \phi_{t} \in(1,5)$. The estimated annual volatility of the return series is defined as $\Phi_{t}\left[x_{t}\right]=\sqrt{\sum_{t=1}^{T} \varsigma_{t}^{d}}$ where the time index for $\Phi_{t}\left[x_{t}\right]$ is at the annual frequency.

An alternative to Merton's procedure (which makes use of squared highfrequency returns) is that proposed by Ghysels, Santa-Clara and Valkanov (2006): the computation of realized absolute variation and bipower variation, which make use of absolute returns. We generate these measures from the firm-level daily data, and find that when aggregated to the annual frequency they were correlated above 0.93 with our Merton-based proxy. Since these measures appear to be rather close substitutes for the Merton-based measures, we do not make further use of them in the empirical work.

The daily returns series are taken from CRSP. For the market index returns, we use returns on the S\&P 500 index, inclusive of dividends.

\section{Empirical findings}

\subsection{Data}

The estimation sample consists of an unbalanced panel of manufacturing firms for the 1984 to 2003 period drawn from Standard and Poor's Industrial

along with its merits. 
Annual COMPUSTAT database. ${ }^{15}$ There are 9,895 firm-years for which the replacement value of the real capital stock may be imputed by the method of Salinger and Summers (1983). A number of sample selection criteria are then applied. We only consider firms which have not undergone substantial changes in their composition during the sample period (e.g., participation in a merger, acquisition or substantial divestment). As these phenomena are not observable in the data, we calculate the growth rate of each firm's real total assets, and trim the annual distribution of this growth rate by the 5th and 95th percentiles to remove firms exhibiting substantial changes in their scale. Values of the investment-to-capital, cash flow-to-capital, debt-tocapital ratios and Tobin's $Q$ outside the 5-95th percentile range are judged implausible. Firms in clear financial distress or those facing substantial liquidity constraints are excluded. One per cent from either end of the annual returns distribution is trimmed. The final data set contains 4,028 firm-years pertaining to 402 firms with complete data for all variables used in the analysis. ${ }^{16}$

Descriptive statistics for the variables used in the analysis are presented in Table 1. The average (median) investment rate for our sample is about $10 \%$ (8.6\%). From the mean (median) of the sample we see that firms' cash flow is equal to over $21 \%(17 \%)$ of the replacement value of their capital stock, comparable to the figures in several relevant studies. The average value for $Q$ of 2.37 is higher than its median, 1.76. The distribution of the debt-to-capital ratio over firms has a mean of 0.53 and a median of 0.33 . The last three lines, labeled as $\eta, \varepsilon$ and $\nu$ give the summary statistics for the constructed measures of uncertainty obtained from firm stock returns, $\mathrm{S} \& \mathrm{P}$ index returns and the covariance between firm and market returns, respectively.

\footnotetext{
${ }^{15}$ We utilise COMPUSTAT data items Shares outstanding (item25), Share price (item199), Total assets (item6), Long term debt (item9), Short term debt (item34), Cash flow (item14+item18) and Investment (item128).

${ }^{16}$ Empirical results drawn from the full sample yielded qualitatively similar findings. The screened data are used to reduce the potential impact of outliers upon the parameter estimates.
} 


\subsection{The link between uncertainty and capital investment}

In what follows we present our results in Table 2 obtained using the dynamic panel data (DPD) approach developed by Arellano and Bond (1991), as implemented in Stata by Roodman (2007). All models are estimated in first difference terms to eliminate unobserved heterogeneity using the one-step GMM estimator on an unbalanced panel from a sample including 402 firms' annual data.

In column one, we start our investigation estimating a standard investment model which includes the basic explanatory variables for firm level investment $\left(Q, C F_{t} / K_{t-1}\right.$ and $\left.B_{t-1} / K_{t-2}\right)$ along with the lagged dependent variable, augmented by the measure of intrinsic uncertainty $\left(\eta_{t-1}\right)$ and its interaction with $C F_{t} / K_{t-1}$. The $J$ statistic (and the corresponding $p$-value) is the Hansen-Sargan test statistic and it indicates that the test for overidentifying restrictions is satisfactory. Furthermore, we reject the presence of second-order autocorrelation $(A R(2))$ validating the use of suitably lagged endogenous variables as instruments. ${ }^{17}$ In this model, neither $Q$ nor the cash flow/assets ratio appear significant, but the lagged measure of intrinsic uncertainty has a negative and highly significant coefficient, while the interaction of the cash flow ratio with intrinsic uncertainty possesses a positive, significant coefficient estimate. This is an interesting finding as Leahy and Whited (1996) report that uncertainty affects investment behavior through $Q$ (in their analysis the coefficient on their proxy for uncertainty becomes insignificant with the introduction of $Q$ ). In our case, even in the presence of $Q$ (although insignificant), intrinsic uncertainty significantly affects the firm's fixed investment behavior, not only on its own but through the interaction with cash flow. ${ }^{18}$

\footnotetext{
${ }^{17}$ The second through fourth lags of $\left(I_{t-1} / K_{t-2}\right), Q_{t},\left(C F_{t} / K_{t-1}\right),\left(B_{t} / K_{t-1}\right)$ and lagged uncertainty measures are employed as GMM instruments.

${ }^{18}$ The sceptical reader may be concerned about the possibility that $\mathrm{Q}$ may be measured with error (See Erickson and Whited (2000)). To dispel concerns that the use of lagged variables as instruments may not overcome an issue of $\mathrm{Q}$ mismeasurement, we tested the model by replacing Q with the ratio of $\left(I / K_{t+1}+I / K_{t+2}\right) /\left(2 I / K_{t}\right)$, following the approach taken in Almeida et al. (2004). With that change made, the qualitative findings of Table 2 are virtually unchanged. The uncertainty proxies and interactions retain their significance, even though this "perfect foresight" approach yields highly significant coefficients on the alternative measure. We therefore consider that potential measurement error in Tobin's
} 
In column two of Table 2, we present the findings from a model augmented with extrinsic uncertainty $\left(\varepsilon_{t-1}\right)$ and its interaction with the cash flow ratio. The cash flow ratio itself is highly significant, while the interaction term lacks significance. Nevertheless, the lagged extrinsic uncertainty term appears with a negative and significant coefficient. Column three presents a model containing both intrinsic and extrinsic factors. In this specification, the interaction effect of intrinsic uncertainty is significant, and extrinsic uncertainty now displays a negative and highly significant coefficient with no meaningful interaction effect. The main effect of intrinsic uncertainty is not statistically significant. Given the coefficients' magnitudes in column three, intrinsic uncertainty is likely to have a stimulative effect on investment while extrinsic uncertainty has an offsetting negative effect.

Column four augments this model with the covariance term $\left(\nu_{t-1}\right)$ and its interaction with cash flow, both of which have significant coefficients (negative for the main effect, positive for the interaction). At the same time, the main effects of intrinsic and extrinsic uncertainty become insignificant, while their interactions with cash flow retain significance. Consequently, our final specification drops the insignificant main effect terms.

In the model of column five, intrinsic uncertainty plays a significant and stimulative role when interacted with the cash flow ratio. This implies that as uncertainty increases the firm's investment increases, with the investment rate becoming more sensitive to changes in cash flow. In contrast, extrinsic uncertainty has a significant negative coefficient on the interaction term: an increase in market-based uncertainty decreases the incentive to invest at any level of cash flow. Perhaps this finding suggests cautious behavior of managers as in Bloom et al. (2007) when uncertainty increases. Finally, we observe that both the main effect and the indirect effect through the CAPMbased uncertainty term are significant. While the direct effect is negative, the indirect effect is positive. Given the coefficients' magnitudes, the net effect of an increase in CAPM-based uncertainty will be negative for the median firm. Taking all effects into account, the firm's rate of investment becomes more sensitive to available cash flow with an increase in uncertainty.

$\mathrm{Q}$ is not seriously biasing our findings. 
This result, supporting the implications of CAPM theory, is quite interesting and stands in clear contrast to the findings reported by Leahy and Whited (1996) (although their model did not incorporate an interaction with cash flow). In the model of column five, the cash flow ratio and debt ratio play important roles in conjunction with uncertainty while Tobin's $Q$ is generally insignificant.

Overall, our findings imply that uncertainty affects fixed capital investment mainly through cash flow, with effects differing in sign. The overall cash flow sensitivity of investment is an increasing function of uncertainty except for Market (extrinsic) uncertainty. When Market uncertainty increases, the impact of cash flow is reduced. This can be explained in the light of the findings of Beaudry et al. (2001), who show that an increase in macroeconomic uncertainty would lead to a negative impact on firms' investment behavior as firm managers will not be able to readily distinguish good from bad investment projects. Hence, in a more volatile environment, managers will be more reluctant to fund a specific project with more uncertain returns.

\subsection{The impact of cash flow and uncertainty}

In order to gauge the sensitivity of cash flow as uncertainty changes across the sample space, we calculate selected percentiles of the empirical $C F_{t} / K_{t-1}$ distribution (using the point and interval estimates from the last column of Table 2) and plot the impact of uncertainty on investment. That is, for each measure we report $\partial(I / K) / \partial$ (uncertainty) as the $C F_{t} / K_{t-1}$ ratio changes. ${ }^{19}$ The point estimates and $95 \%$ confidence interval for each derivative are computed and plotted in Figure 1. Even a casual inspection of these derivatives shows that the role of uncertainty on firm investment is not trivial, and varies considerably across types of uncertainty, in line with arguments put forth by Boyle and Guthrie (2003). ${ }^{20}$ In particular, one can see that an increase in the firm-level $(\eta)$ uncertainty measure leads to an increase in

\footnotetext{
${ }^{19}$ Tables of numerical values underlying the graphs are available from the authors upon request.

20 "... . any attempt to empirically identify the relationship between uncertainty and investment will pick up offsetting uncertainty effects unless the exact nature of the uncertainty is carefully identified." (p. 2160)
} 
investment, with that effect strengthened for higher levels of liquidity.

When we turn to interpreting the effects of the CAPM-based $(\varepsilon)$ uncertainty measure, we find that they are altered by the size of the firm's cash flow. When the firm's cash flow is low, an increase in CAPM-based uncertainty leads the firm to curtail its capital investment. However, as cash flow increases, the impact of CAPM-based uncertainty $(\nu)$ becomes insignificant as Panel $\mathrm{C}$ in Figure 1 shows. In contrast, as Panel B illustrates, higher levels of market-based uncertainty $(\epsilon)$ reduce investment, more vigorously as liquidity increases.

Table 3 presents estimates of the elasticity of investment with respect to cash flow as each measure of uncertainty takes on high, low or median values. High values are those at or above the empirical $70^{t h}$ percentile of the distribution, while low values are at or above the empirical $30^{\text {th }}$ percentile of the distribution. Although this table is prescriptive and does not necessarily reflect observed combinations of the measures of uncertainty, the results presented in Table 3 show the firms' reaction to uncertainty as mirrored in the estimated parameters from our model. Effectively, this table is a reflection of the results that we depict in Panels A and B of Figure 1. Notice that the impact of cash flow differs across different uncertainty levels. A $100 \%$ increase in cash flow will have differing stimulus on investment given the level of uncertainty, ranging from $8 \%$ to $23 \%$. Furthermore, the biggest effect is registered as Market $(\varepsilon)$ uncertainty rises or falls between high and low levels. This is quite understandable as the impact of market uncertainty on capital investment is negative when all other variables are held constant. For the other two types of uncertainty $($ Own $(\eta)$ or CAPM-based $(\nu)$ ), the impact of changes in cash flow varies much less with uncertainty. These findings strongly indicate that models that ignore the cash flow-uncertainty interaction are likely to compute misleading estimates of the effect of cash flow. That effect may vary significantly when the magnitude and type of uncertainty that affects the firm and its environment is taken into account. 


\section{Conclusions}

In this paper we investigate the analytical and empirical linkages between firms' capital investment behavior and financial frictions, as proxied by their liquidity and magnitude of uncertainty. We specifically concentrate on the role of firm-specific (intrinsic), market-specific (extrinsic) and CAPM-based measures of uncertainty on firms' investment spending in that relationship, allowing for interactions with cash flow. Both idiosyncratic and market uncertainty measures are constructed using a method based on Merton (1980) from the intra-annual variations in stock returns using firm level stock prices and S\&P 500 index returns. Employing annual data obtained from COMPUSTAT for manufacturing firms over the period between 1984-2003 we then investigate the linkages between investment, cash flow and uncertainty.

Our empirical analysis of the data provides several interesting findings. The CAPM-based uncertainty measure yields a direct negative effect on investment. This is notable as earlier research has not been successful in verifying the analytical prediction. The data also suggest that uncertainty measures affect fixed capital investment mainly through cash flow, enhancing or reducing the role of cash flow on the investment behavior of the firm. In contrast to results from the earlier literature, we show that these effects may differ in sign. We find that an increase in intrinsic uncertainty stimulates investment spending, with an effect increasing in liquidity. CAPMbased uncertainty has significant effects on investment which vary in sign depending on the firm's level of cash flow. Finally, an increase in extrinsic uncertainty has a dampening effect on investment spending, inducing managers to become more cautious.

Our findings are unique in light of previous studies, which have not shown such diverse and significant effects. In contrast to the financial frictions literature, we show that uncertainty measures have an effect on investment behavior of the firm even in the presence of $Q$, debt, and a measure of cash flow. We also show that the impact of cash flow on capital investment changes as the underlying uncertainty varies. This result implies that models that ignore the cash flow-uncertainty interaction are likely to compute misleading estimates of the effect of cash flow. Given these findings, further 
exploration along these lines could shed considerable light on the effects of interactions between uncertainty and firm liquidity when investigating the role of financial frictions on the firm's capital investment behavior. 


\section{References}

Abel, A. B. (1983), 'Optimal investment under uncertainty', American Economic Review 73, 228-233.

Abel, A. B. and Eberly, J. C. (2002), Investment and q with fixed costs: An empirical analysis, working paper, University of Pennsylvania.

Almeida, H., Campello, M. and Weisbach, M. (2004), 'The cash flow sensitivity of cash', Journal of Finance 59(4), 1777-1804.

Arellano, M. and Bond, S. (1991), 'Some tests of specification for panel data: Monte Carlo evidence and an application to employment equations', Review of Economic Studies 58(2), 277-97.

Baum, C. F., Caglayan, M. and Ozkan, N. (2004), 'Nonlinear effects of exchange rate volatility on the volume of bilateral exports', Journal of Applied Econometrics 19, 1-23.

Baum, C. F., Caglayan, M. and Talavera, O. (2008), 'Uncertainty determinants of firm investment', Economics Letters 98(3), 282-287.

Beaudry, P., Caglayan, M. and Schiantarelli, F. (2001), 'Monetary instability, the predictability of prices and the allocation of investment: An empirical investigation using UK panel data', American Economic Review 91(3), 648-662.

Bernanke, B. S. (1983), 'Irreversibility, uncertainty, and cyclical investment', Quarterly Journal of Economics 98, 85-106.

Bloom, N., Bond, S. and Van Reenen, J. (2007), 'Uncertainty and investment dynamics', Review of Economic Studies 74(2), 391-415.

Blundell, R., Bond, S., Devereux, M. P. and Schiantarelli, F. (1992), 'Investment and Tobin's Q: Evidence from company panel data', Journal of Econometrics 51, 233-257.

Bond, S. R. and Cummins, J. G. (2004), Uncertainty and investment: An empirical investigation using data on analysts' profits forecasts, Finance 
and Economics Discussion Series 2004-20, Board of Governors of the Federal Reserve System.

Boyle, G. W. and Guthrie, G. A. (2003), 'Investment, uncertainty, and liquidity', The Journal of Finance 58(5), 2143-2166.

Brainard, W., Shoven, J. and Weiss, L. (1980), 'The financial valuation of the return to capital', Brookings Papers on Economic Activity 2, 453502 .

Caballero, R. J. (1999), Aggregate investment, in J. Taylor and M. Woodford, eds, 'Handbook of Macroeconomics', Vol. 1B, North-Holland, Amsterdam.

Calcagnini, G. and Saltari, E. (2000), 'Real and financial uncertainty and investment decision', Journal of Macroeconomics 22, 491-514.

Campa, J. M. and Goldberg, L. S. (1995), 'Investment in manufacturing, exchange rates and external exposure', Journal of International Economics 38, 297-320.

Craine, R. (1989), 'Risky business: The allocation of capital', Journal of Monetary Economics 23, 203-218.

Darby, J., Hallett, A. H., Ireland, J. and Piscatelli, L. (1999), 'The impact of exchange rate uncertainty on the level of investment', Economic Journal 109, C55-C67.

Dixit, A. K. and Pindyck, R. S. (1994), Investment under Uncertainty, Princeton University Press, Princeton.

Driver, C. and Moreton, D. (1991), 'The influence of uncertainty on aggregate spending', Economic Journal 101, 1452-1459.

Edmiston, K. D. (2004), 'Tax uncertainty and investment: A cross-country empirical examination', Economic Inquiry 42, 425-40.

Erickson, T. and Whited, T. M. (2000), 'Measurement error and the relationship between investment and q', Journal of Political Economy 108(5), 1027-1057. 
Ferderer, P. J. (1993), 'The impact of uncertainty on aggregate investment spending: An empirical analysis', Journal of Money, Credit and Banking 25, 30-48.

Ghosal, V. and Loungani, P. (1996), 'Product market competition and the impact of price uncertainty on investment: Some evidence from US manufacturing industries', Journal of Industrial Economics 44, 21728 .

Ghysels, E., Santa-Clara, P. and Valkanov, R. (2006), 'Predicting volatility: getting the most out of return data sampled at different frequencies', Journal of Econometrics 127(1-2), 59-95.

Goldberg, L. S. (1993), 'Exchange rates and investment in United States industry', Review of Economics and Statistics 75, 575-589.

Guiso, L. and Parigi, G. (1999), 'Investment and demand uncertainty', Quarterly Journal of Economics 114, 185-227.

Hartman, R. (1972), 'The effects of price and cost uncertainty on investment', Journal of Economic Theory 5, 258-266.

Hennessy, C. A. (2004), 'Tobin's Q, debt overhang and investment', Journal of Finance 59, 1717-1742.

Hubbard, R. G., Kashyap, A. K. and Whited, T. M. (1995), 'Internal finance and firm investment', Journal of Money Credit and Banking 27(4), 683701.

Huizinga, J. (1993), 'Inflation uncertainty, relative price uncertainty and investment in US manufacturing', Journal of Money, Credit and Banking 25, 521-554.

Hurn, A. and Wright, R. E. (1994), 'Geology or Economics? Testing models of irreversible investment using North Sea oil data', Economic Journal 104, 363-71. 
Leahy, J. V. and Whited, T. M. (1996), 'The effect of uncertainty on investment: Some stylized facts', Journal of Money, Credit and Banking 28(1), 64-83.

Love, I. (2003), 'Financial development and financing constraints: International evidence from the structural investment model', Review of Financial Studies 16, 765-791.

Merton, R. C. (1980), 'On estimating the expected return on the market: An exploratory investigation', Journal of Financial Economics 8, 323-61.

Minton, B. A. and Schrand, C. (1999), 'The impact of cash flow volatility on discretionary investment and the costs of debt and equity financing', Journal of Financial Economics 54, 423-460.

Pindyck, R. S. and Solimano, A. (1993), 'Economic instability and aggregate investment', National Bureau of Economic Research, Macroeconomic Annual pp. 259-303.

Roodman, D. M. (2007), 'XTABOND2: Stata module to extend xtabond dynamic panel data estimator', available at: http://ideas.repec.org/c/boc/bocode/s435901.html. Accessed 14 March 2007.

Salinger, M. and Summers, L. (1983), Tax reform and corporate investment: A microeconomic simulation study, in M. Feldstein, ed., 'Behavioral Simulation Models in Tax Policy Analysis', University of Chicago Press.

Serven, L. (2003), 'Real-exchange-rate uncertainty and private investment in LDCs', Review of Economics and Statistics 85, 212-18. 


\section{Figure 1. Estimated sensitivities from interactions model}
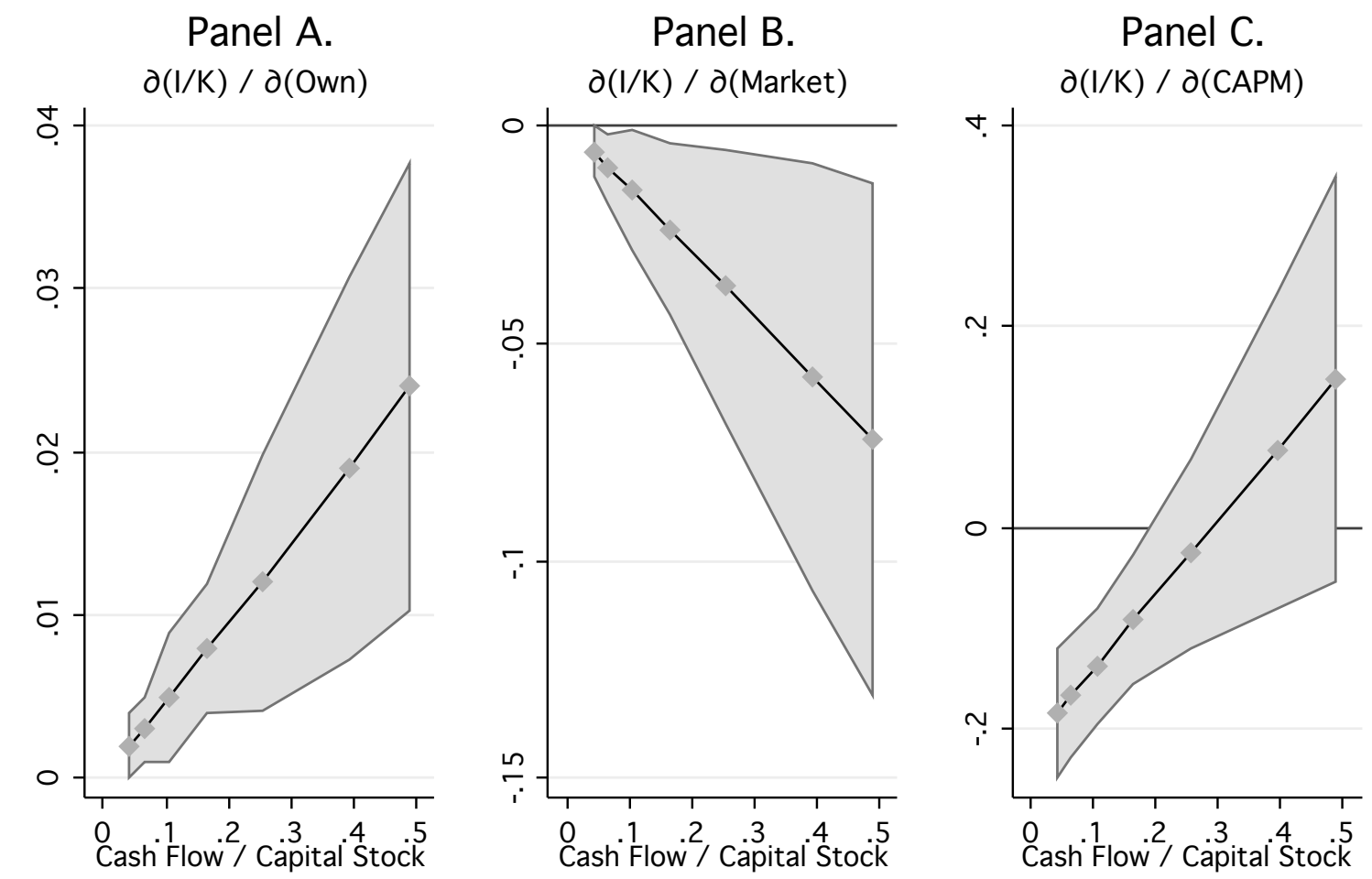

95\% confidence interval shaded

Percentiles: 5, 10, 25, 50, 75, 90, 95 
Table 1: Descriptive statistics

\begin{tabular}{lrrrrr}
\hline \hline & $\mathrm{p} 25$ & $\mathrm{p} 50$ & $\mathrm{p} 75$ & mean & $\mathrm{sd}$ \\
\hline Investment rate & 0.0545 & 0.0861 & 0.1304 & 0.1017 & 0.0631 \\
Tobin's Q & 0.9387 & 1.7557 & 3.0788 & 2.3717 & 2.0132 \\
Cash flow/K & 0.1071 & 0.1711 & 0.2701 & 0.2111 & 0.1540 \\
Debt/K & 0.1853 & 0.3287 & 0.6079 & 0.5295 & 0.7041 \\
$\eta_{t}$ & 0.4618 & 0.7067 & 1.0890 & 0.8489 & 0.5547 \\
$\varepsilon_{t}$ & 0.0875 & 0.1842 & 0.2953 & 0.2101 & 0.1404 \\
$\nu_{t}$ & 0.0217 & 0.0456 & 0.0866 & 0.0620 & 0.0567 \\
\hline \hline
\end{tabular}

Notes: The sample size is 4,028 firm-year observations. $p 25, p 50, p 75$ are the quartiles of the variables, while $s d$ are their standard deviations. The investment rate is the ratio of investment to the lagged replacement value of the capital stock, $K_{t-1}$. The cash flow and debt ratios are defined similarly. The $\eta_{t}$ term is a measure of intrinsic uncertainty, while $\varepsilon_{t}$ refers to extrinsic uncertainty and $\nu_{t}$ is the CAPM-based risk measure. 
Table 2: Robust Difference GMM estimates of the investment rate

\begin{tabular}{|c|c|c|c|c|c|}
\hline & $(1)$ & $(2)$ & $(3)$ & $(4)$ & $(5)$ \\
\hline \multirow{2}{*}{ 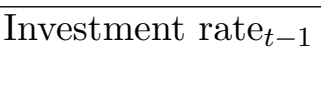 } & $0.458^{* * *}$ & $0.465^{* * *}$ & $0.492^{* * *}$ & $0.496^{* * *}$ & $0.466^{* * *}$ \\
\hline & $(0.035)$ & $(0.034)$ & $(0.031)$ & $(0.031)$ & $(0.034)$ \\
\hline \multirow{2}{*}{ Tobin's $Q_{t}$} & 0.002 & -0.002 & -0.000 & -0.001 & -0.001 \\
\hline & $(0.002)$ & $(0.001)$ & $(0.001)$ & $(0.001)$ & $(0.001)$ \\
\hline \multirow[t]{2}{*}{ Cash flow ratio $t$} & 0.037 & $0.178^{* * *}$ & $0.106^{* * *}$ & $0.111^{* * *}$ & $0.106^{* * *}$ \\
\hline & $(0.035)$ & $(0.030)$ & $(0.031)$ & $(0.030)$ & $(0.029)$ \\
\hline \multirow[t]{2}{*}{ Debt ratio $_{t-1}$} & $-0.014^{* * *}$ & -0.004 & $-0.011^{* * *}$ & $-0.010^{* * *}$ & $-0.012^{* * *}$ \\
\hline & $(0.004)$ & $(0.004)$ & $(0.003)$ & $(0.003)$ & $(0.004)$ \\
\hline \multirow[t]{2}{*}{$\eta_{t-1}$} & $-0.029 * * *$ & & -0.005 & -0.001 & \\
\hline & $(0.005)$ & & $(0.005)$ & $(0.005)$ & \\
\hline \multirow{2}{*}{$\mathrm{CF}$ ratio $\times \eta_{t-1}$} & $0.115^{* * *}$ & & $0.062^{* * *}$ & $0.051^{* *}$ & $0.049 * * *$ \\
\hline & $(0.024)$ & & $(0.023)$ & $(0.023)$ & $(0.015)$ \\
\hline \multirow[t]{2}{*}{$\varepsilon_{t-1}$} & & $-0.037^{* * *}$ & $-0.033^{* *}$ & 0.011 & \\
\hline & & $(0.013)$ & $(0.015)$ & $(0.021)$ & \\
\hline \multirow[t]{2}{*}{$\mathrm{CF}$ ratio $\times \varepsilon_{t-1}$} & & 0.035 & -0.015 & $-0.181^{*}$ & $-0.146^{* *}$ \\
\hline & & $(0.068)$ & $(0.071)$ & $(0.117)$ & $(0.062)$ \\
\hline \multirow{2}{*}{$\nu_{t-1}$} & & & & $-0.182^{* * *}$ & $-0.216^{* * *}$ \\
\hline & & & & $(0.062)$ & $(0.039)$ \\
\hline \multirow[t]{2}{*}{$\mathrm{CF}$ ratio $\times \nu_{t-1}$} & & & & $0.667^{*}$ & $0.744^{* * *}$ \\
\hline & & & & $(0.343)$ & $(0.258)$ \\
\hline \multirow[t]{2}{*}{ Constant } & $0.051^{* * *}$ & $0.029^{* * *}$ & $0.034^{* * *}$ & $0.033^{* * *}$ & $0.040 * * *$ \\
\hline & $(0.006)$ & $(0.004)$ & $(0.004)$ & $(0.004)$ & $(0.004)$ \\
\hline$J$ & 333.802 & 339.624 & 371.893 & 372.155 & 367.610 \\
\hline$J$ pvalue & 0.569 & 0.480 & 0.999 & 1.000 & 0.583 \\
\hline $\operatorname{AR}(2)$ & -0.591 & -0.491 & -0.402 & -0.457 & -0.628 \\
\hline $\operatorname{AR}(2)$ pvalue & 0.554 & 0.623 & 0.688 & 0.648 & 0.530 \\
\hline
\end{tabular}

Notes: The sample size is 3,411 firm-year observations derived from 402 firms. The investment rate is the ratio of investment to the lagged replacement value of the capital stock, $K_{t-1}$. The cash flow (CF) and debt ratios are defined similarly. The $\eta_{t-1}$ term is a measure of intrinsic uncertainty, while $\varepsilon_{t-1}$ refers to extrinsic uncertainty and $\nu_{t-1}$ is the CAPM-based risk measure. 
Table 3: Elasticities of investment with respect to cash flow

\begin{tabular}{rrrrr}
\hline \hline Own & Market & $C A P M$ & Estimated & Estimated \\
$\eta$ & $\epsilon$ & $\nu$ & Elasticity & Std.Error \\
\hline High & High & High & 0.16 & 0.03 \\
High & High & Low & 0.15 & 0.03 \\
High & Low & Low & 0.22 & 0.03 \\
High & Low & High & 0.23 & 0.04 \\
Median & Median & Median & 0.20 & 0.03 \\
Low & Low & High & 0.15 & 0.03 \\
Low & High & High & 0.08 & 0.03 \\
Low & High & Low & 0.07 & 0.03 \\
Low & Low & Low & 0.14 & 0.02 \\
\hline \hline
\end{tabular}

Low: uncertainty measure at or below the $30^{\text {th }}$ percentile. Median: uncertainty measure at the $50^{t h}$ percentile. High: uncertainty measure at or above the $70^{t h}$ percentile. 